\title{
High-growth firms in transport sector (Russian experience)
}

\author{
Dmitri Pletnev ${ }^{1 *}$, Kseniia Naumova ${ }^{1}$, Saeed Mirvahedi $^{2}$ \\ ${ }^{1}$ Chelyabinsk State University, 129, Br. Kashirinykh st., 454001, Chelyabinsk, Russia \\ ${ }^{2}$ Allameh Tabataba'i University, Dehkadeh-ye-Olympic, Tehran, Iran
}

\begin{abstract}
High-growth firms provide a substantial stake in the national economy growth and supply job creation. Research of gazelle stability, allocation and success play an essential role in understanding the manufacturing and economic growth overall. The paper aims to present the results of high-growth firms analysis in the Russian transport sector. The authors propose the high-growth firms' detection methods based on accounting data and analyze the allocation of high-growth firms according to the sectors ( railway and highway transport) and by federal districts of Russia. The authors define total revenue trends of high-growing firms comparing with ordinal firms and inside transport sectors. This study pays special attention to the evaluation of the further high-growth firms' success in 2016-18. The most common phenomenon of high-growth firms is sacrificing the profit to achieve an accelerated growth rate.
\end{abstract}

\section{Introduction}

The high-growth firm (HGF, gazelles) phenomenon helps to explain internal drivers of economic growth based on realization of entrepreneurial potential. The authors emphasize interconnection of economic growth and job creation by HGFs. The transport sector as one of the vital scope of activities, has such success and growth trends that represent the growth of the national economy. That is why the research of HGFs and their specific features in the transport sector is a significant scientific work.

The focal point in high-growth firms or gazelles studies is research of D. Birch [3], who found a new economic phenomenon of such little group of firms with fine contribution in job creation and growth of state economy. He offered an algorithm of gazelle identification. The gazelle should have an annual revenue growth rate of no less than $20 \%$ for five years. Later the 5-year criterion was reduced to 3 or 4 years. There was no common point of view about the growth rate barriers, the duration of continuous growth, the limitation of the staff size and other criteria till OECD decree a standard definition of HGFs as "all enterprises with average annualized growth greater than twenty percent per annum, over three years, and with ten or more employees at the beginning of the observation period. Growth is thus measured by the number of employees and by turnover." $[1,11]$.

\footnotetext{
*Corresponding author: pletnev@csu.ru
} 
D.J. Storey [16, 17] and R. Barkham, G. Gudgin, M. Hart, E. Hanvey [2] placed emphasis on the importance of gazelles for economy. HGFs have a significant effect on the economic and social environment by fast creating new jobs, leading economic growth and stability.

S.-O.Daunfeldt and D. Halvarsson.'s [6] investigation shows the fact that high-growth firms are only "one-hit wonders," and there is low probability for prolonging or repeating their success in the future period. F.Moreno and A.Coad's research demonstrates another forcible fact about high-growth firms. So the average age of HGFs is younger than non-HGFs and it is supposed to be an inverse relationship between age and high growth [11]. R.Brown, S.Mawson, C.Mason prepared a list of myths about HGF. Firstly, it is not a strict rule that only young and small firms can become 'a gazelle'. Of course, small operation firms can quickly achieve a $20 \%$ rate of growth rather than a big firm. Another myth is that HGFs stick to a steady linear growth. The idiosyncrasies of firm growth patterns and the varied capabilities of TMTs mean that most firms struggle and encounter severe 'growing pains'. In addition, there is a connection between the location of a firm and its ability of high growth. The myth is that gazelles are irrespective of their location. There are tons of different factors that contribute to growth and start with close availability to key distribution facilities, government policy, the stability of the economic environment and others [4]. The idea that high-growth firm location patterns follow a certain economic logic discussed by M. Li, S.J.Goetz, M.Partridge, D.A.Fleming [8] and M.Cowell, S.Lyon-Hill, S. Tate [5]. The scholars found a system of location feature which is specific for gazelles. C.Masona, R.Brownb, M. Hartc and M.Anyadike-Danesc [10] held a broad research of Scotland gazelles. They focused on specific features of Scotland HGFs, which differ from their counterparts in the rest of the UK for the worse in size and contribution to creating local employment. But the aggregate analysis indicates that location is not a barrier to business growth. Furthermore, the scholars accept the same side as R.Brown, S.Mawson, , C.Mason, , that the majority of gazelles are not high-tech firms. This fact still firmly roots in the scientific community as well as in the entrepreneurship policy sphere [10]. From the other point of view, E. Litau claims that firm development is independent from any external factors and the success of firm, especially HGF, is explained by talented entrepreneurs and it is necessary to solve the informational challenge to avoid growth blocks [9].

M. Krošláková, V. Kubičková, L. Jurkovičová, N. Kubiniy note a nonstandard feature of gazelles during economic crises: "gazelles behave in an anti-cyclical way and do not react to rising recession" [7].

Scientific reserve of authors in this field comprises some previous papers about Russian high-growth companies. D. Pletnev analyzes the dynamics of the whole number of small and medium firms in Russia and detects gazelles in aggregate. Then the scholars research the success pathway of HGFs with key factors based on public sources, financial accounting, interviews of entrepreneurs and other instruments [13]. In many cases, Russian gazelles have the same characters as European. Post-crisis analysis shows that the success of HGF, assessed by their ability to generate profits, was significantly higher than that of ordinary companies $[13,14]$. Pletnev D.A. distinguishes key natural features of Russian HGF, thus only a third of them is entrepreneurial, the rest are affiliated with large corporations, with the state ones or with VIP, and their advantages and disadvatages are often explained by a change in the attitude of the parent structure to the company itself [15].

\section{Materials and Methods}

An updated criterion of a minimal $20 \%$ growth rate has been used for three years to define a high-growth firm (Birch [3], Pletnev [13]). 
There is a verification of different hypotheses about HGF stability in subsequent |periods, differences in sizes of ordinal firms and gazelles in railway and highway sectors, irregularity of local allocation of HGFs and success using ROS criterion.

The Russian rating agency «FIRA PRO» has been studied as a database of financial accounting of Russian firms for hypothesis testing. A firm's size is limited by applying no less than 50,000,000 rubles operating income criterion for the initial year of observation (2012).

Initially, the financial and qualitative data of 1230 Russian transport companies have been obtained for 2012-2018 periods. The outliers are excluded from the sample (firms with abnormal or missing financial data). The sample is limited by the growth rate revenue more than -0.9 and less than 9.0, and by ROS (more than -0.5 and less than 2.0). The result of data processing is adjusted sample of 993 firms.

There are three time periods 2016, 2017 и 2018 for gazelle identification, which have been used in the analysis. This period graduation allows doing dynamic analysis in the transport sector and evaluating the stability of transport HGF in Russia. Based on the collected reliable dataset, the firms have been decompounded to federal districts and sectors.

\section{Results}

Among 993 firms sample, only 18 high-growth firms in 2016 were identified. 138 firms do business by railway transportation and it is about $14 \%$ of the whole sample. Other 855 firms use road transport. Such a minority of railway transport was formed by not a well-developed net of railways in Russia compared with the level of the of railway infrastructure in the countries of North America and Western Europe or Japan. Direct attention to an interesting fact that only one gazelle belongs to the railway sector. Therefore we can conclude that it is extremely hard to achieve sustained growth of income in the railway transportation industry.

The results of F.Moreno, A.Coad were verified and we calculated the average age in samples of gazelles and non-gazelles. The age of non-gazelles is 14.95 year while the gazelle age is 14.86. So we can't conclude that the Russian transport HGF has the same characteristics as European HGF.

Among 993 firms only 29 firms have features of HGF at least in one observation period (2016, 2017 or 2018). We detect 18 transport firms to be a gazelle in 2016. In 2017 just ten companies from the entire sample are HGF. In 2018 the number of HGFs growths to 11 firms.

Only 5 out of 18 firms save HGF position в 2017. Moreover, two firms prolong success and stay HGF in 2018. The results show that high growth is unstable and changes the phase to stability or even to deceleration of functioning (fig. 1).

HGFs take a share of $1.8 \%$ of the whole sample. There are some interesting facts in sector segmentation of sample so that among 138 railway transport firms, only 3 firms $(2 \%)$ are gazelles, and among 855 highway transport firms, there are 26 gazelles (3\%). Railway HGF in average are bigger, rather than highway transport HGF (see fig.2)

We present transport firms and HGF allocation by federal districts in fig. 3. To prove the significance of data matching, we decide to separate two major Federal Cities of Moscow and Saint-Petersburg into detached groups. The prevalent share of successful firms is located in Siberian and Central Federal Districts. The smallest share of them is in Ural and NorthWest Federal Districts and Federal Cities. However, the share of the whole sample firms is higher than HGFs in these districts. 


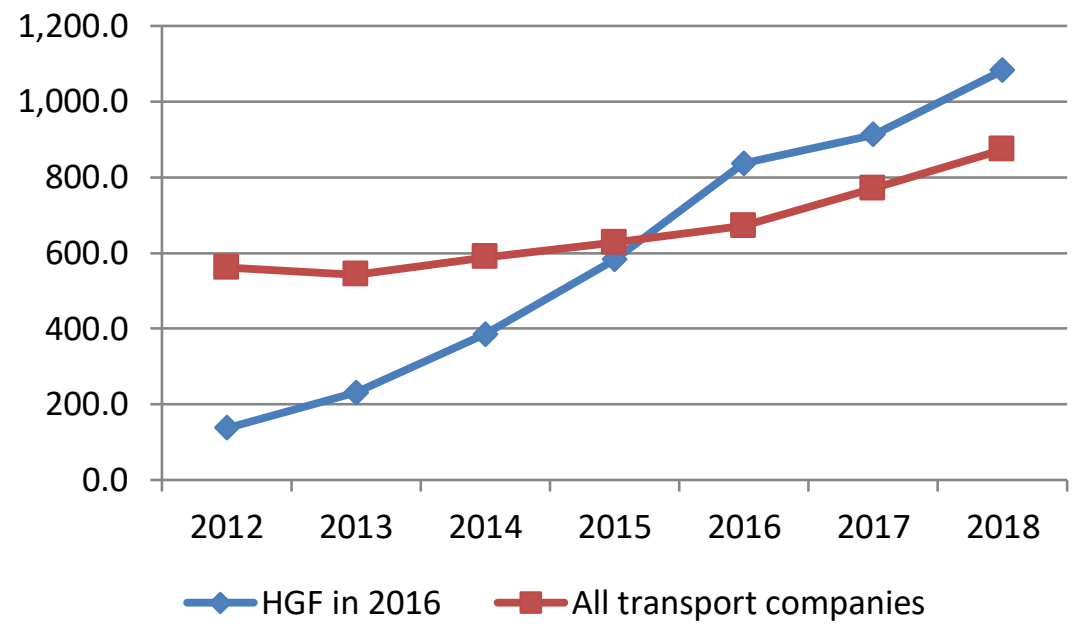

Fig.1 Average total revenue of Russian transport companies (in total and HGF)

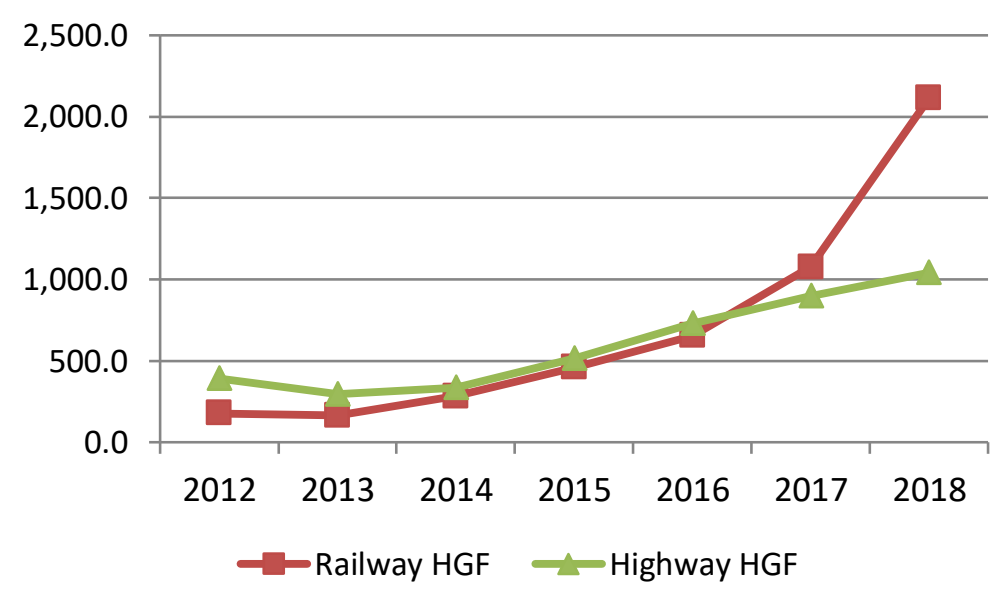

Fig.2 Average revenue of Russian transport HGF by sector

We proceed with the analysis of the success estimation of Russian transport HGF comparing with all transport firms (table 1). The average ROS coefficient of transport firms is growing from 5.4\% in 2016 up to 12.6 in 2018. Also, railway transport firms show a higher ROS level (up to $21.5 \%$ in 2018). At the same time, the average revenue growth rate of all transport firms is $7.1 \%$ in 2016 and $14.8 \%$ in 2017 with slowdown in 2018. Gazelles ROS indicator growth in the observation period is stable but slower than the whole sample rate. However, the revenue indicators show a dropping trend from $42 \%$ in 2016 to $25.5 \%$ in 2018. Railway transport HGFs have a rapid growth starting with a negative ROS parameter in 2016 and running to $13.3 \%$ in 2018 . We can see the opposite trend for highway transport HGFs from $3.4 \%$ in 2016 to $2.2 \%$ in 2018 . The same opposite trends are presented in revenue growth results. Ordinal railways firms and HGFs have the same trend to growth when highway firms and highway HGFs fall slowly. Hence, gazelles cannot resist negative influence which affects the whole sector commonly. The fact that HGFs have significantly less ROS value comparing with sample level is notable and as equal for railway and highway transport firms. 


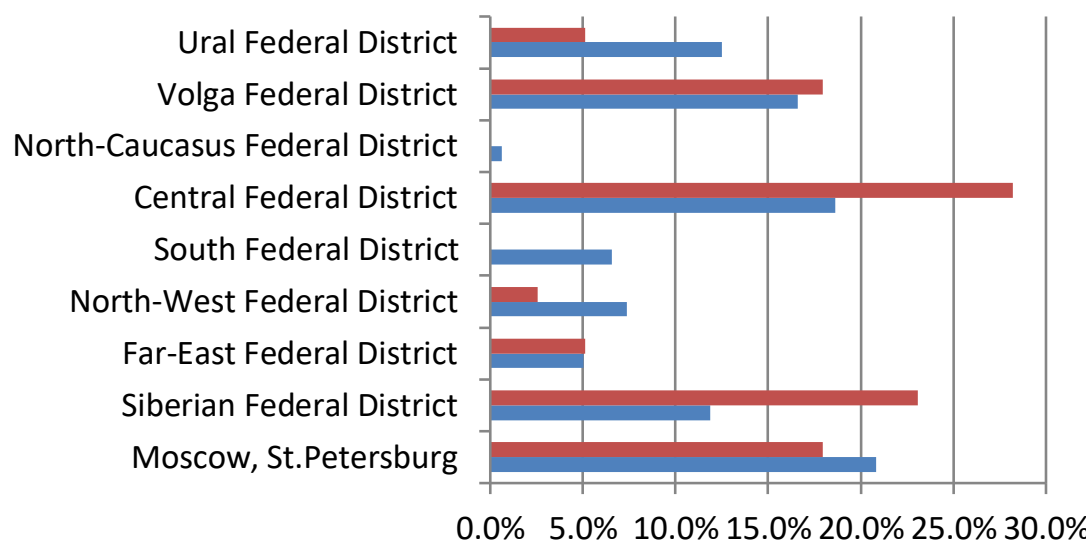

Share among HGF $\quad$ Share in total, \%

Fig. 3 Regional structure of transport sector in Russia by number of firms (in total and among HGF)

Table 1. Business success of Russian transport HGF (2016-2018)

\begin{tabular}{|l|r|r|r|r|r|r|r|r|}
\hline & \multirow{2}{*}{$\begin{array}{c}\text { Number of } \\
\text { Companies }\end{array}$} & \multirow{2}{*}{$\begin{array}{c}\text { Share } \\
\text { in total }\end{array}$} & \multicolumn{4}{|c|}{ ROS, \% } & \multicolumn{3}{|c|}{ Revenue growth rate, \% } \\
\cline { 5 - 10 } & 138 & $13.9 \%$ & 7.7 & 17.8 & 21.5 & 2.6 & 14.6 & 16.4 \\
\hline $\begin{array}{l}\text { Railway } \\
\text { companies }\end{array}$ & 855 & $86.1 \%$ & 2.9 & 2.8 & 2.1 & 12.5 & 14.9 & 10.0 \\
\hline $\begin{array}{l}\text { Highway } \\
\text { companies }\end{array}$ & 993 & $100.0 \%$ & 5.4 & 10.7 & 12.6 & 7.1 & 14.8 & 13.4 \\
\hline $\begin{array}{l}\text { All transport } \\
\text { companies }\end{array}$ & 3 & $0.3 \%$ & -3.2 & 5.7 & 13.4 & 42.6 & 64.6 & 96.4 \\
\hline Railway HGF & 26 & $2.6 \%$ & 3.4 & 2.9 & 2.2 & 41.9 & 23.1 & 15.7 \\
\hline Highway HGF & 29 & $2.9 \%$ & 2.8 & 3.2 & 4.3 & 42.0 & 27.0 & 25.5 \\
\hline All transport HGF & & & & & & & & \\
\hline
\end{tabular}

\section{Conclusion}

During the research on transport high-growth firms in Russia, we made some main conclusions. Firstly, only a small part of firms in the transport sector of the Russian economy has an HGF status. HGFs took $1.8 \%$ in 2016, only $0.5 \%$ in 2017 and $0.02 \%$ in 2018 of the sample could stay a gazelle. Being a gazelle is an unstable position so that firms have serious barriers for prolonged success. Only 5 (28\%) of gazelles were able to survive in 2017 and $2(11 \%)$ in 2018 . We determine sharp differences between HGFs in railway and highway transport sectors (the first category gazelles have faster growth and they are stable, the size of railway firms are bigger). District allocation of HGFs in Russia is heterogeneous.

The most significant part of HGFs located in the Central Federal district, and the smallest part is in North Caucasian and Ural Federal districts. It is necessary to highlight the fact, that Moscow and Saint-Petersburg have not a prevalent part of HGFs and this fact is contrary to the popular point of view that the most successful enterprises are located only in major cities. Moreover, HGFs have significantly less level of ROS. We can explain this nonstandard fact 
by the system of gazelle financial resources concentration. They prefer to put resources into achieving high growth rather than have top gains.

The ordinal firm average age is approximately equal to the average gazelle's age. There are evidences that only young firms can become HGF. We suspect the continued research may give new significant results about Russian high-growth firms in other sectors of economy and can be supplemented by researching success factors such as gender, ownership structure, company age and others.

The reported study was funded by RFBR, project number 20-510-92006

\section{References}

1. D.B. Audretsch, Determinants of High-Growth Entrepreneurship (Copenhagen, 2012).

2. R. Barkham, G. Gudgin, M. Hart, E. Hanvey. The Determinants of Small Firm Growth: An Inter-Regional Study in the United Kingdom 1986-90, (London, UK, 1996). doi:10.4324/9780203059777.

3. D.L. Birch. The Public Interest 65, 3-14 (1981)

4. R. Brown, S. Mawson, C. Mason. Entrepreneurship \& Regional Development 29 (5-6), 414-443 (2017). doi:10.1080/08985626.2017.1291762.

5. M. Cowell, S. Lyon-Hill, S. Tate. Journal of Enterprising Communities 12(2), $178-$ 198 (2018). doi:10.1108/JEC-08-2017-0064.

6. S.-O. Daunfeldt, D. Halvarsson. Small Business Economics, 44 (2), 361-383 (2015). doi:10.1007/s11187-014-9599-8.

7. M. Krošláková, V.Kubičková, L. Jurkovičová, N. Problems and Perspectives in Management 13(2), 27-35 (2015).

8. M. Li, S.J. Goetz, M. Partridge, D.A. Fleming. Entrepreneurship \& Regional Development 28 (1-2), 97-125 (2016). doi:10.1080/08985626.2015.1109003.

9. E. Litau, Journal of Advanced Research in Law and Economics 8(6), 1812-1824 (2017). doi:10.14505/jarle.v8.6(28).16.

10. C. Masona, R. Brown, M. Hartc, M. Cambridge Journal of Regions, Economy and Society 8(2), 343-358 (2015). doi:/10.1093/cjres/rsu032.

11. F. Moreno, A. Coad, Advances in Entrepreneurship, Firm Emergence and Growth, 17, 187-230. (2015). doi: 10.2139/ssrn.2743181.

12. OECD. High-Growth Enterprises: What Governments Can Do to Make a Difference. (2010)

13. D.A. Pletnev, E.V. Nikolaeva. Eurasian Studies in Business and Economics book series (EBES), 3(1) 115-127 (2016). https://doi.org/10.1007/978-3-319-27570-3_11

14. D. Pletnev, V.Barkhatov. Springer Proceedings in Business and Economics (to be published) (2020)

15. D. Pletnev, E.Nikolaeva. Economic and social development, 16, 96-104 (2018). doi:10.24411/1994-2796-2019-10315.

16. D.J. Storey. Research in Organization Behavior 17, 171-222 (1994)

17. D.J. Storey. Understanding the Small Business Sector. (Cengage Learning, Boston, Massachusetts, USA, 2010). 